\title{
Los refranes en las Tradiciones peruanas de Ricardo Palma
}

\author{
Eduardo Huárag Álvarez \\ Pontificia Universidad Católica del Perú, Lima - Perú \\ ehuarag@pucp.pe
}

\section{Resumen}

En el presente artículo se analiza la importancia de los refranes y decires en las Tradiciones peruanas. Siendo un tipo de comunicación, una costumbre, un uso del lenguaje y la manera de expresar un conocimiento de la realidad o de los aconteceres sociales, los refranes se encuentran enraizados en la cultura iberoamericana. Han existido siempre, aunque en el período romántico cobran una particular importancia dado el interés por el folclore popular. A través del análisis de varias tradiciones de Ricardo Palma, ponemos en evidencia la importancia de los refranes y la manera cómo los inserta en el relato de las mismas.

Palabras claves: refranes, oralidad, cognoscitiva, folclórica, romántica, tradiciones.

\section{Abstract}

This article discusses the importance of proverbs and sayings in the Peruvian Traditions. Being a type of communication, a tradition, a type of language usage and a way to express understanding of realities or social occurring, proverbs are rooted in the Ibero-American culture. They have always existed, although in the romantic period they become particularly important due to the interest of the romantics in popular folklore. Through the analysis of several traditions by Palma, we can demonstrate the importance of proverbs and the way they are inserted into a story such as Peruvian Traditions.

Keywords: proverbs, orality, cognitive, folk, romantic, traditions. 
Eduardo Huarag Álvarez, Doctor en Lengua y Literatura por la Pontificia Universidad Católica del Perú. Maestría en Comunicaciones por la Universidad de Andalucía (España). Profesor Asociado del departamento de Humanidades de la Pontificia Universidad Católica del Perú. Ha sido profesor visitante en la Universidad de Burdeos, la Universidad de Múnich y la Universidad de São Paulo. Ha publicado "La cultura oral en la narrativa hispanoamericana", "Mitos de origen y el trasmundo en las culturas prehispánicas y amazónicas”, entre otros. 


\section{Los refranes como manifiesto cultural}

Los refranes y decires son frases cortas que utilizan los hablantes en determinadas circunstancias y cuando el contexto de comunicación tiene relación con el refrán. Se trata, pues, de un recurso verbal almacenado en la memoria de los hablantes de diferentes comunidades. Están presentes como manifiestos culturales que parecen imponerse muchas veces con fines prácticos, amparados en probables situaciones similares que, precisamente, dieron motivo al refrán o proverbio.

Explicada la presencia del refrán, es probable que esta tendencia a registrar los dichos y decires transformados en refranes haya existido siempre. El lenguaje fue siempre el vehículo a través del cual el hombre manifiesta su interpretación de los hechos de la realidad y aún de la vida cotidiana.

Lo que sucede es que los conocimientos académicos y la escritura fueron de uso y manejo de círculos exclusivos. La ilustración estuvo muy ligada a ese tipo de conocimiento. Por otro lado, la población mayoritaria vivía haciendo uso de la oralidad en cuyo ámbito se revela el reiterado uso de refranes y decires. En algún momento, quizá luego de la Edad Media, la brecha se amplía entre quienes se desenvuelven en la cultura oral y, de otro, los que desdeñan la cultura oral porque es un razonamiento muy elemental y superficial que al crear un refrán simplifica el análisis y la interpretación de la realidad.

Por otro lado, hay que decir que los que pertenecían al pueblo, no tenían acceso a la cultura institucional. De tal manera que su actividad cognoscitiva provenía de aquello que recibía de oídas y que se convirtió en una especie de enciclopedia de saberes que conservaba en su memoria. 
Lo interesante es que cuando aparecen los registros culturales, el teatro castellano o los relatos breves, no en pocos casos se hará mención a los refranes que utilizaban los personajes. De modo que el afán de configurar personajes populares con sentido de autenticidad, necesariamente tenía que considerar la retórica del aldeano y en ello iba todo el registro de refranes y decires propios del pueblo.

No olvidemos que las manifestaciones de la cultura oral, la cultura del pueblo o, como algunos dicen, su sabiduría popular, era considerada como las razones del vulgo: reflexiones nada rigurosas ni de valor científico como las que proceden de los grupos académicos o la filosofía institucionalizada. Hay aquí una contraposición entre los saberes académicos y de ausente rigor analítico y, de otro, el registrado por la cultura popular desde tiempos inmemoriales. Lo concreto es que ese conocimiento popular, esa sabiduría popular se ha mantenido en esa especie de biblioteca ambulante del ciudadano. En esa confrontación entre el lenguaje y la praxis cotidiana, el hablante saca sus conclusiones y adecúa los hechos al refrán; o el refrán se equipara a las experiencias recogidas.

Según Louis Combet: "estos refranes expresan una concepción del mundo y de la vida social muy cercana a la que nos proponen los refraneros actuales" (2018, p. 823).

Sin duda, se trata de aceptar que estamos ante un tipo de conocimiento que tiende a simplificar los aconteceres de la realidad. Esto se aplica a refranes antiguos como "A quien madruga, Dios ayuda", "Más vale pájaro en mano, que ciento volando, "La mujer honrada, la pierna quebrada".

El análisis de los refranes no es tan sencillo. Algunos pueden analizarlo de manera aislada u optar por una clasificación de acuerdo con la orientación que ellos tienen. Pero hay 
quienes consideran que el refrán o los decires no pueden ser descontextualizados. Si nos remontamos a los orígenes del refrán en la literatura castellana, veremos que estos se hacen evidentes en La Celestina y luego en la narrativa picaresca. $\mathrm{Y}$ es que la incorporación del personaje pícaro demandaba, por autenticidad, la necesaria incorporación de una de sus características: su retórica de hablante marginal con las adecuaciones o transgresiones de la oralidad. Entonces, para configurar un personaje popular, para expresar su modo de ser, recurrían a su retórica.

Esto lo podemos apreciar de manera nítida en El Quijote, de Cervantes. Allí, frente a Alonso Quijano, don Quijote de la Mancha, hombre bien leído e ilustrado, surge un personaje popular, glotón que, aunque no tiene lecturas, es pragmático. Si su retórica no convence al Quijote, puede recurrir al aspecto emocional para impedir que su amo siga con aventuras que tendrán un mal final. El Quijote insistirá en que se trata de personajes reales y Sancho lamentará que su amo tome decisiones erróneas y termine maltrecho. Aun así, seguirá acompañándolo en la esperanza de obtener el gobierno de una ínsula, como se le había ofrecido. A estas alturas, no es posible imaginar la novela de Cervantes sin Sancho Panza. Él hace el contrapeso al Quijote, hombre reflexivo, atrapado en ese imaginario que le hace ver el asedio constante de personajes malignos. Es el justiciero, pero su mirada alucinada debe complementarse con la de Sancho, un personaje dicharachero que a cada situación le aplica un refrán.

Por su lado, Lázaro Carreter (1978) aclara que la literatura escrita se difunde o se redescubre aún años después de ser escrita; mientras que "un cantar o un refrán creados y no asimilados se desvanecen para siempre”. De modo que la colectividad juega un rol importante en esa creación anónima. Existe mientras la comunidad la hace suya y la mantiene. Pero digamos, además, 
que el refrán puede ser oído en comunidades indistintas y no siempre mantiene los mismos términos referidos o el sentido de la frase. Al cambiar alguna palabra para que concuerde en rima, con otro término, puede producirse un desplazamiento semántico.

\section{Los refranes, la hispanidad y el romanticismo}

Pero centrémonos en Ricardo Palma. Como se sabe, Palma siguió los lineamientos de la tendencia literaria romántica. Una tendencia que no se reduce al tratamiento de temas sentimentales, amores apasionados o la debacle emocional ante amores frustrados. El romanticismo fue un movimiento que -al contrario del neoclasicismo, que se centraba en el canon clásico y academicista- predicó una literatura que fuera al encuentro de los relatos y trovas populares. El romanticismo rescata el folclore popular y valora las historias que se difunden en la oralidad cultural, al margen de la cultura oficial y la Ilustración. Los románticos predican la libertad y la independencia del artista. El creador es autónomo y representa la reafirmación del individualismo. Su inconformismo con el presente lo lleva a la evasión en el tiempo y en el espacio. Por eso la preferencia por escribir tradiciones sobre la época de la Colonia.

Mientras a los neoclásicos les interesan los ideales universales, a los románticos les interesa la historia popular, la pequeña historia, el incidente anecdótico, porque a través de ello se puede revelar aspectos de la condición humana. Ana Romeo y Lourdes Domenech (2018) anotan que "El costumbrismo (español) es la manifestación más importante de la prosa romántica. Es el resultado de una minuciosa observación de la realidad, pero de una realidad especialmente popular, folclórica y pintoresca" ( $\mathrm{p}$. $3)$. 
Señalan dichas autoras que uno de los propósitos de los costumbristas fue ofrecer "el reflejo de una realidad ignorada por el historiador" (Ibíd.). Y es eso precisamente lo que hizo Palma. Nuestro tradicionista reescribió la historia de la Colonia, esos siglos XVI, XVII y XVIII en los que los españoles se aposentaron en América. Es cierto que hay una especie de principios contradictorios: cultivan y defienden su libertad y postura individual, pero a la vez reflejan en su obra -como Palma- los manifiestos colectivos, sociales, de una realidad cultural.

Isabelle Tauzin considera que "Los dichos y refranes se convierten en imprescindibles ingredientes, agregados a las versiones posteriores cuando no figuran en la primitiva" (1999, p. 61). Pareciera que, por el estilo y gusto estético, el narrador intuyera que la presencia de refranes oportunos acercan el hecho anecdótico a la cultura popular y el reconocimiento del ingenio del narrador. Tauzin agrega, en una nota al pie, que en la tradición "La conspiración de la saya y el manto", Palma modificó el final del primer párrafo agregando un dicho: "Ni el trigo es mío ni es mía la cibera; conque así, muela el que quiera" (Ibíd.).

\section{Los refranes y el análisis de algunas tradiciones}

En las tradiciones de Palma desfilan personajes e incidentes que dejaron frases o refranes que la colectividad recordaría. Sin duda, en los tiempos de la consolidación de la conquista española, a Palma le interesa Francisco de Carbajal, personaje que hacía gala de su ingenio, su humor y sarcasmo para enfrentar los hechos e incidentes, aun los que le eran desfavorables. En "Comida acabada, amistad terminada", los hechos que se narran suceden en tiempos de la guerra que se declararon los conquistadores. Palma dedica varias de sus tradiciones a 
Francisco de Carbajal, personaje singular entre los españoles que vinieron a la conquista.

En el relato, Carbajal estaba a órdenes de Gonzalo Pizarro y tenía preso a Francisco Hurtado. Al encontrarse con el detenido, recordó que fueron amigos en tiempos de la niñez. Luego se fueron juntos para participar en un banquete y, como era la costumbre, el invitado debía pronunciar algunas palabras de agradecimiento. Carbajal dijo que había cumplido con el amigo al liberarlo de la cárcel. Pero a continuación dijo también: "es menester que cumpla con lo que debo al servicio del gobernador, mi señor. ¿No encuentra vuesa merced fundadas mis razones?" (Palma, 1968, pp. 88-89). El señor Hurtado consideró esa reflexión como muy justa. Entonces Carbajal le anunció que daría la orden de ejecutarlo con el garrote. Y como para cerrar su orden, no dejó de recurrir a un refrán: "Cumplí hasta el fin con el amigo, que buey viejo hace surco derecho. Comida acabada, amistad terminada" (p. 89, cursivas nuestras).

Con el refrán se revela la severa y cruel decisión que no deja de tener un tono de ironía y sarcasmo. Para Carbajal, el banquete no era sino un hecho incidental y que él anteponía a la amistad su condición de subordinado a un gobernante.

Algunas veces, Palma titulaba sus tradiciones con el mismo refrán que comentará. De este modo, el narrador espera que el lector asocie el incidente con el refrán. En su defecto, se asocie el incidente al personaje. Esto sucede con la tradición titulada "Si te dieran hogaza, no pidas torta".

Pero antes hagamos un paréntesis. Como se sabe, Carbajal fue uno de los personajes que más le simpatizó a Palma. Y se cuenta que más allá de su temperamento, el personaje estaba destinado a quedarse en el Perú. Solo así se explica que cuando Carbajal estaba por irse a España y había vendido todos sus bienes, tuvo 
un serio impase. Y fue que no encontró navío que lo llevara a la península. Y fue allí que pronunció el refrán: “el hombre propone y Dios dispone” (p. 86) Y de ese modo decidió que el último tramo de su vida la pasaría en el Perú.

Volvamos a la tradición cuyo título es un refrán. Se cuenta que Carbajal tenía ante sí a cuatro soldados a los que debía ejecutar. Uno de ellos se identificó y, por su nombre, a Carbajal le recordó que podía ser el hijo de un gran amigo. No se equivocó. Y fue por eso que decidió que le perdonaría la vida. Pero a Martín Betanzos se le ocurrió hacer un pedido adicional: "Pues tanta merced me hace su señoría, quisiera que para que mejor pueda llevar mi obligación, mande que se me devuelva mi caballo, siquiera para que pueda alzar los pies del suelo" (p. 87).A Carbajal, aquella petición le pareció un exceso. Y como siempre tenía en la memoria algunos de los refranes castellanos, en su respuesta recurriría a ello: "iHola! iHola! ¿Danle hogaza y quiere torta? Ya te dirán de misas, bellaco. Eres como el abad de Compostela, que se comió el cocido y aún quiso la cazuela" (Ibíd.).

Y como para completar su reflexión recurrirá a una explicación que termina siendo una cruel ironía de lo que pidió el soldado: "Mira Caracciolo, ahórcame luego a este barbilindo, y sea de un árbol y de manera que tenga los pies bien altos del suelo, todo cuanto él sea servido" (Ibíd.). De esa manera, se cumplía la voluntad del soldado que quería su caballo para alzar los pies del suelo.

En otras de sus tradiciones, los refranes se pueden mezclar con los decires. Lo concreto es que refranes y decires pertenecen a la cultura oral, aquella que recurre al repertorio cuando un hecho acontecido viene muy al caso. No deja de ser importante, como particular estilo de Palma, el que por entonces los refranes reflejen ese ingenio propio de los españoles y los criollos. 
Ingenio que, incluso en situaciones de riesgo, sale a relucir para salvar la vida de un desdichado. Esto sucede en la tradición titulada "Las hechas y por hacer". En aquel entonces se cuenta que Carbajal tenía como preso a un tal Cosme Hurtado a quien le perdonó la vida para que se encargue de curar las heridas de los caballos. Luego le haría una advertencia: "te perdono las hechas y por hacer" (p. 93).

Esto no es exactamente un refrán puesto que no tiene su estructura típica en el que suele aparecer una frase condicional. Hurtado estaba feliz con el favor recibido. Pero diose el caso que cuando Carbajal enfrentó a Diego Centeno, algunos de sus soldados se fugaron al bando enemigo. Carbajal venció a Centeno y capturó a Cosme Hurtado. Carbajal le dijo que esta vez no se salvaría de la horca. A lo cual Cosme Hurtado respondió: "No puede ser, señor don Francisco, que vuesa señoría es hombre de palabra y empeñada la tiene para dejarme con vida -contestó con desparpajo el prisionero" (p. 94).

Carbajal niega que le haya hecho alguna concesión. Entonces el prisionero le recuerda el famoso dicho que meses antes le dijo ante varios testigos: "Vueseñoría me dijo un día en público y de testificarlo hay más de diez, que me perdonaría las hechas y por hacer" (Ibíd.).

El soldado había resultado ingenioso y hábil para utilizar la frase. Ante lo dicho, a Carbajal no le quedó otra posibilidad que aceptar la palabra empeñada: "iMiren por dónde se apea el bellaco! -murmuró Carbajal-. Y lo peor es que dice cierto, y que resguardo tiene en mi palabra de caballero" (p. 94).

Carbajal dejó libre a Hurtado porque en esos tiempos más que un documento impreso o contrato escrito, lo que predominaba era el compromiso de palabra. No olvidemos que por entonces 
predominaba la cultura oral y que lo dicho y prometido era palabra y honor empeñados.

Se suele decir que los refranes condensan la sabiduría popular. Recogen la experiencia observada en casos semejantes. Eso es lo que sucede cuando Palma quiere contar acerca de un incidente ocurrido en Potosí. El narrador cuenta que cinco años después que descubrieran el mineral, fueron tantos los aventureros que arribaron a la aldea que alcanzó a tener veinte mil pobladores. Los que llegaban, sea por la ansiedad, sea por la fortuna que conseguían fácilmente, se aficionaron a participar en los juegos prohibidos y las apuestas. Esto da motivo al refrán: "Pueblo minero [...] pueblo vicioso y pendenciero" (p. 123).

Al hecho anecdótico o los incidentes melodramáticos, Palma agrega incidentes que revelan -de alguna manera- la situación de injusticia de los notables o mestizos contra los indígenas. $\mathrm{Al}$ parecer, el sistema y las instituciones estaban hechas para que no se tuviera en cuenta el testimonio del indígena. Una marginalidad que confirmaba las condiciones de opresión de un sistema en el que los indígenas eran ciudadanos invisibilizados.

Según el relato, un nativo mostró una piedra que revelaba contener o ser parte de un valioso mineral. Se la mostró a los españoles y ellos se afanaron en que les dijera dónde la había encontrado. El indio se negó a darles la información requerida.

Una vez en su pueblo, el gobernador le dijo: "Mira, compadre, [...] tú no puedes trabajar la mina sin que los viracochas te maten para quitártela. Denunciémosla entre los dos, que conmigo vas seguro, pues soy autoridad y amigos tengo en palacio" (p. 353).

El indio confió en él, pero el mestizo gobernador hizo los trámites de registro de la mina sin considerar al indio. Este se quejó ante el virrey, que luego de escuchar su alegato dijo 
que no había forma de probar que él era dueño de la mina. Los documentos confirmaban que la mina le correspondía al mestizo.

Entonces el indio se retiró y le dijo a su burro: "iArre, borrico! Quien nació para pobre no ha de ser rico" (p. 354).

Una información importante es que Palma no se reduce al uso de los refranes que ciertas circunstancias así lo ameritan. El escritor advierte los cambios o mutaciones que se pueden haber producido en ciertos refranes. En la tradición que comentaremos, Gabriel Leguizamo se siente muy enamorado de una joven. Se gasta una fortuna para satisfacer los caprichos de la mujer amada. Después se enteraría que el Teniente gobernador del Cuzco "era el amante titular" (p. 219).

El caso es que una tarde ambos personajes se encontraron en la calle y Gabriel no saludó a la autoridad, como era costumbre en esos tiempos. La autoridad hizo respetar su posición social y ordenó que le capturen y le castiguen. Cuando se iba a cumplir con la decena de azotes que se estableció, se suspendió la ejecución hasta el día siguiente. El joven Gabriel Leguizamo dijo: "Ya me han sacado a la vergüenza y lo que falta no vale la pena de volver a empezar. El mal trago, pásalo pronto. Puesto en el burro... aguantar los azotes. iArre pollino! (p. 220).

Lo interesante es que el narrador agregó: "Tal es el origen del refrán que algunos cambian por este otro: «Puesto en el borrico, igual da ciento que ciento y pico»" (Ibíd., comillas del autor). Palma es observador de los cambios o mutaciones de los refranes. Se da cuenta de que los refranes pueden tener cambios en el léxico debido, especialmente, a la preferencia de los hablantes por aquellos términos que más se ajustan a sus usos y giros idiomáticos. 
En otras tradiciones, Palma no deja de hacer reflexiones cuando observa esas mutaciones en los refranes. Eso sucede en la tradición conocida como "Carta canta". Dice Palma:

Hasta mediados del siglo XVI vemos empleada por los más castizos prosadores o prosistas castellanos, esta frase: rezan cartas, en la acepción de que tal o cual hecho es referido en epístolas. Pero de repente las cartas no se conforman con rezar, sino que rompieron a cantar, y hoy mismo, para poner remate a una disputa, solemos echar mano al bolsillo y sacar una misiva diciendo: -Pues, señor, carta canta-. Y leemos en público las verdades o mentiras que ella contiene. Lo que es la gente ultracriolla no hace rezar ni cantar a las cartas, y se limita a decir: papelito manda (pp. 146-147).

A propósito del refrán, Palma consigna un hecho anecdótico. Y fue el caso que un mayordomo de Barranca decidió enviar melones con dos mitayos. Ellos llevarían los melones al patrón, pero a medio camino se les antojó comer uno de los melones. Para evitar ser denunciados, escondieron la carta que envió el mayordomo. Los nativos pensaban que en esa grafía había una especie de espíritu que podría observarlos.

Horas después, uno de los mitayos hizo la observación que si llevaban las cajas así como estaban, el patrón se daría cuenta que en uno hay 4 melones y en otro 5. De manera que, para que estuvieran emparejadas, se comieron otro melón.

Ya en Lima, el patrón leyó la carta y observó que lo traído no correspondía con la información anotada: "Las cartas dicen que diez y ustedes se han comido dos por el camino... iEa! Que les den una docena de palos a estos pícaros" (p. 148).

Luego de recibir el castigo, uno de los mitayos dijo: "iLo ves, hermano? iCarta canta!” (Ibíd.). Según Palma, el refrán pasó el 
mar, por lo que debería ser considerado como un peruanismo y se pasará la vida reclamando ante la Real academia que se le considere como tal.

Lo concreto es que cada refrán reclama un tipo de estudio distinto. En este caso, creemos que aquello de reza carta se adecuaba más a esos tiempos de espíritu medieval y de mucha difusión eclesial. Conforme se hace al uso pasa a un término más común a la oralidad: carta canta. Y años después, cuando predomina la vida administrativa y burocrática, se impone aquello de "papelito manda".

Hemos dejado para el final ese tipo de personajes que se conoce muchos refranes y en cuanto empieza no tiene cuándo acabar porque enlazan un refrán tras otro.

El narrador cuenta que un zapatero tenía por concubina a una tal Casilda que andaba en guiños con Antuco Quiñones. El caso es que el zapatero tuvo que viajar de Huamanga a Huanta. Y sucede que al volver encontró que la puerta de su casa estaba cerrada por dentro. En eso, apareció una anciana que, al parecer, era de las que se meten en todo acontecimiento del barrio. Doña Pulqueria le dijo:

-No te canses, Periquillo, que si esperas a que tu mujer venga a abrir, tarea te doy hasta el día del juicio por la noche; que la mujer, como el vino, engaña al más fino. Y aunque bocado de mal pan, ni lo comas ni lo des a tu can, avísote que, desde que volviste la espalda, alzó el vuelo la paloma, y está muy guapa en el palomar de Quiñones, que, como sabes, es gavilán corsario. Por lo demás, hijo, en lo que estamos, benedicamos, y confórmate con la lotería que te ha caído, que, en este mundo redondo, quien no sabe nadar se va al fondo. $\mathrm{Y}$ aunque mal me quieren mis comadres porque digo las verdades, ponte erguido como gallo en cortijo, y no te des a 
pena ni a murria, que eso sería tras de cornamenta, palos, y motivo para que hampones y truchimanes te repitan: modorro, ya entraste en el corro. Deja a un lado la vergüenza o dala un puntapié, que la vergüenza es espantajo que de nada sirve y para todo es atajo: verde es la vergüenza y se la come el burro de la necesidad. Calma, muchacho, y no des con esa tu furia y fanfurriña vagar para que yo piense que predico en desierto y que en cabeza de asno se pierde la lejía, que aunque el decidor sea loco, el escuchador ha de ser cuerdo, y cada gorrión aguante su espigón, y sobre todo, no hay mal de amores que no se cure, ni pena por hembra que no se olvide. Y ten presente que el bobo si es callado, por sesudo es reputado, y que muchos están en la jaula por demasiado ir al aula [...]. De pagártelas habrá con las setenas, que Casilda y Quiñones son tal para cual, y a ruin mozuelo, ruin capizayuelo, y el mejor día la planta en mitad del arroyo y cátate vengado que, como dice el refrán: ¿con quién la hábedes, cuaresma?, con quien non vos ayunará. Y cuenta que los refranes y sentencias son evangelios chiquitos, que dicen más verdad que la bula de composición, y los inventó Salomón, que fue un rey más sabio que el virrey Esquilache... (pp. 451 - 452).

Con este personaje y con esta reflexión del narrador volvemos a lo que decíamos al inicio: los refranes condensan los conocimientos acumulados en la memoria de la colectividad. Refranes y sentencias que pueden ser comparados a los evangelios que, de alguna forma, son un razonamiento condensado sobre la vida humana. 


\section{Bibliografía}

Carreter, L. (1978). "Literatura y el folklore: los refranes". Recuperado de http://www.cervantesvirtual.com/obra/literatura-y-folklore--losrefranes-0/ en setiembre de 2018 .

Combet, L. (2018). "Los refranes en la literatura". Recuperado de http://www.euskaltzaindia.eus/dok/euskera/49706.pdf en setiembre de 2018.

Palma, R. (1968). Tradiciones peruanas completas. Madrid: ediciones Aguilar.

Romeo, A. y Domenech, L. (2018). “El Romanticismo”. Recuperado de www.materialesdelengua/LITERATURA/HISTORIA/LITERATURA/ LARRA/f_LARRA romanticismo-caracteristicas.pdf en septiembre de 2018.

Tauzin, I. (1999). Las tradiciones peruanas de Ricardo Palma: claves de una coherencia. Lima: Editorial universitaria.

Recibido el 09 de enero del 2019 Aprobado el 10 de enero del 2019 